\title{
Refluxo gastroesofágico em cães anestesiados: fisiopatologia, clínica, diagnóstico e terapêutica
}

\author{
Gastroesophageal reflux in anesthetized dogs: physiopathology, clinic, diagnosis \\ and therapeutics
}

\author{
Evandro Silva Favarato ${ }^{I}$ Maria Verônica de Souza ${ }^{I *}$ Paulo Renato dos Santos Costa ${ }^{I I}$
}

\section{- REVISÃO BIBLIOGRÁFICA -}

\section{RESUMO}

\begin{abstract}
O refluxo gastroesofágico pode afetar várias espécies e apresenta diversas etiologias, sendo as anestesias gerais uma das principais causas de esofagite em cães, devido à redução do tônus do esfincter esofagogástrico, ocasionada por fármacos anestésicos. São fatores responsáveis pela lesão esofágica em consequência do refluxo, o tipo do material refluido, o volume, a frequência, a duração do refluxo e a integridade da mucosa esofágica. É importante prevenir o refluxo durante a anestesia, devido ao risco de ocasionar além da esofagite pós-operatória, outras graves complicações como a formação de estenoses esofágicas ou ainda resultar em pneumonia por aspiração. Para isso, é importante estabelecer protocolos anestésicos que não modifiquem a função do esfincter esofagogástrico, bem como determinar estratégias terapêticas que reduzam a incidência do refluxo. Neste artigo, são revisados os aspectos anatômicos e fisiológicos da junção esofagogástrica, assim como os relacionados com o refluxo gastroesofágico em cães anestesiados.
\end{abstract}

Palavras-chave: esfincter esofagogástrico, esofagite, pHmetria esofágica, anestesia geral, procinéticos.

\section{ABSTRACT}

Gastroesophageal reflux can affect various species and presents several etiologies, and general anesthesia can be considered one of the main causes of esophagitis in dogs, due to the reduction of the gastroesophageal sphincter tonus caused by anesthetic drugs. There are many factors responsible for the esophageal lesion due to reflux, including type of refluid material, reflux volume, frequency and duration, and esophageal mucosa integrity. It is important to prevent reflux during anesthesia because of the risk of causing not only post operatory esophagitis but also other serious complications such as formation of esophageal stenosis, or aspiration pneumonia. Thus, it is important to establish anesthetic protocols that do not modify the function of the gastroesophageal sphincter, as well as determine therapeutic strategies that could reduce reflux incidence. This research reviews the anatomic and physiological aspects of gastroesophageal junction as well as those aspects related with gastroesophageal reflux in anesthetized dogs.
Key words: gastroesophageal sphincter, esophagitis, esophageal pHmetry, general anesthesia, prokinetics.

\section{INTRODUÇÃO}

$\mathrm{Na}$ medicina humana, a doença do refluxo gastroesofágico (RGE) é definida como uma enfermidade crônica decorrente do refluxo retrógrado de conteúdo gastroduodenal para o esôfago e/ou outros órgãos adjacentes, acarretando sintomas esofágicos ou extra-esofágicos, associados ou não a lesões teciduais (NASI et al., 2006). Em cães, a doença não está bem documentada e o termo refluxo gastroesofágico não representa uma enfermidade como a descrita em humanos, mas apenas a passagem momentânea (episódio) de conteúdo gástrico ou duodeno-gástrico para o esôfago, no qual a redução do tônus do esfincter esofagogástrico (EEG), promovida pela ação dos fármacos anestésicos, é o principal fator envolvido na patogênese (WILSON et al., 2006a).

'Programa de Pós-graduação em Medicina Veterinária, Área de Clínica Médica, Universidade Federal de Viçosa (UFV), Campus Universitário, Viçosa, MG, Brasil.

"Departamento de Veterinária, Área de Clínica Médica, UFV, Campus Universitário, s/n, 36570-000, Viçosa, MG, Brasil. E-mail: msouza@ufv.br. *Autor para correspondência. 
Estudos mostram que o conteúdo refluído no esôfago pode ser oriundo somente do estômago (refluxo ácido) ou pode ser uma mistura de conteúdos gástrico e duodenal (refluxo não ácido ou duodenogástrico). O refluxo ácido é o mais frequente, entretanto o refluxo não ácido tende a causar quadros mais graves de esofagite, devido ao sinergismo das enzimas gástricas e duodenais (GALATOS et al., 2001).

Estudos em cães foram realizados com o objetivo de identificar a incidência do RGE em animais anestesiados, sendo possível verificar a variação de $14,3 \%$ (ANAGNOSTOU et al., 2009) a 55\% (WILSON et al., 2005). A incidência de episódios de refluxo pode variar em função de diferentes fatores, como a idade, o tipo do procedimento cirúrgico (GALATOS \& RAPTOPOULOS, 1995a), a duração do jejum préoperatório e dos fármacos utilizados na medicação préanestésica (GALATOS \& RAPTOPOULOS, 1995b), na indução (RAPTOPOULOS \& GALATOS 1997) e na manutenção da anestesia (HASHIM et al., 1995; WILSON et al., 2006b).

Normalmente se preconiza um jejum alimentar de 12 horas, entretanto há uma variação considerável nos protocolos de restrição alimentar conforme a idade do animal e o procedimento cirúrgico (MUIR, 2007). Diminuição do volume do conteúdo gastrointestinal antes da anestesia, mediante a realização do jejum alimentar e hídrico, é o procedimento mais comumente utilizado para reduzir o risco de refluxo durante o processo anestésico (GALATOS \& RAPTOPOULOS, 1995a; MUIR, 2007). SAVVAS et al. (2009) observaram maior volume gástrico nos cães com jejum pré-operatório de 3 horas quando comparado com os submetidos a 10 horas, demonstrando a importância da privação alimentar antes da anestesia, entretanto notaram grande variação na intensidade do esvaziamento gástrico de acordo com o tipo de alimento ingerido. Dietas secas estavam mais comumente associadas à maior volume gástrico do que enlatadas ou líquidas, sugerindo que jejum pré-operatório prolongado não é garantia de menor volume estomacal.

O risco da ocorrência de RGE também é influenciado pela idade, sendo maior nos cães neonatos e nos geriátricos. Nos primeiros, o fator responsável pela maior incidência é a incompetência do esfíncter esofagogástrico, que possui aproximadamente a metade da capacidade do tônus observado nos adultos (STROMBECK \& GUILFORD, 1996). Nos geriátricos, o fator incriminado é o aumento da acidez do conteúdo gástrico, que por sua vez reduz o tônus do esfíncter esofagogástrico. O posicionamento durante a cirurgia parece não influenciar na incidência dos episódios de refluxo, porém animais submetidos a procedimentos cirúrgicos abdominais e os idosos apresentam maiores riscos de desenvolverem o quadro (GALATOS \& RAPTOPOULOS, 1995b).

O refluxo durante a anestesia torna-se motivo de grande preocupação pelo risco de ocasionar grave esofagite pós-operatória, passível de evoluir para ulceração e formação de estenoses esofágicas, decorrentes do processo cicatricial; ou ainda resultar em pneumonia por aspiração (STROMBECK \& HARROLD, 1985; WILLARD \& WEYRAUCH, 2000; SELLON \& WILLARD, 2003) ou mesmo obstrução das vias aéreas caso o animal não esteja intubado (NG \& SMITH, 2001).

O objetivo do presente estudo foi realizar uma revisão bibliográfica sobre os principais fatores relacionados ao refluxo gastroesofágico em cães, com ênfase na ação dos fármacos anestésicos sobre a junção esofagogástrica e nos principais aspectos clínicos, incluindo métodos de diagnóstico e prevenção do quadro. Embora o foco do trabalho tenha sido a espécie canina, também foram citadas algumas pesquisas com humanos com a intenção de complementar o tema ainda pouco explorado em cães.

\section{DESENVOLVIMENTO}

O esfíncter esofagogástrico representa a junção entre o esôfago e o estômago (TAMS, 2005). Funciona como um esfíncter fisiológico e não como anatômico, pois não é constituído por uma grande massa especializada de músculo e atua como uma zona de alta pressão em descanso, que promove um fluxo unidirecional do esôfago para o estômago, prevenindo assim o refluxo do conteúdo gástrico (WATERMAN \& HASHIM, 1991; STROMBECK \& GUILFORD, 1996; TAMS, 2005). Em cães, o EEG consiste de uma camada externa longitudinal de músculo estriado e uma camada interna circular de músculo liso, que se funde com a camada interna de músculo estriado do esôfago adjacente (STROMBECK \& GUILFORD, 1996; TAMS, 2005). Um estudo manométrico demonstrou que o EEG nos cães apresenta $4,4 \pm 1,69 \mathrm{~cm}$ de comprimento (WATERMAN \& HASHIM, 1991).

O RGE é considerado a causa mais comum de esofagite no cão (ADAMAMA-MORAITOU et al., 2002) e ocorre quando os mecanismos para sua contenção apresentam-se insuficientes, permitindo que o conteúdo gástrico reflua em direção ao esôfago em condições não fisiológicas (MORAES FILHO, 1993; WILLARD \& WEYRAUCH, 2000). Em condições fisiológicas, pode ocorrer uma pequena quantidade de refluxo (TAMS, 2005), devido a episódios transitórios e de curta duração de relaxamento do EEG, que raramente 
acarretam esofagite, devido aos mecanismos de contrações peristálticas secundárias, aos fatores locais protetores de mucosa e à neutralização do meio ácido pela saliva deglutida, que é rica em bicarbonato. São fatores responsáveis pela lesão esofágica em consequência do refluxo, a característica do material refluído, a capacidade de esvaziamento esofágico, o volume e a frequência do refluxo, o período de permanência do material refluído no esôfago e a integridade da mucosa esofágica (STROMBECK \& GUILFORD, 1996).

O refluxo ácido foi por muito tempo considerado como o principal fator desencadeante de esofagite nos episódios de RGE. Sabe-se que o refluxo ácido isoladamente é lesivo, porém, quando associado aos ácidos biliares (refluxo não ácido), pode ser ainda mais lesivo, devido ao sinergismo tóxico das secreções gástricas e duodenais (GALATOS et al., 2001).

Os sinais clínicos da esofagite de refluxo são comuns aos das demais causas de esofagite e incluem regurgitação, anorexia, disfagia, odinofagia e sialorréia, que podem ocorrer nas primeiras 24 horas (SELLON \& WILLARD, 2003), mas normalmente estão presentes entre dois dias a duas semanas após o procedimento anestésico (WILLARD \& WEYRAUCH, 2000).

As principais complicações do RGE em cães são as formações de estenose esofágica, que ocorrem principalmente após a esofagite (SELLON \& WILLARD, 2003) e a pneumonia aspirativa secundária aos episódios de regurgitação, que se apresenta com sinais respiratórios como tosse, taquipnéia ou dispnéia e crepitações difusas (ADAMAMA-MORAITOU et al., 2002; SELLON \& WILLARD, 2003). A estenose esofágica pode ocorrer em qualquer região, entretanto é mais comum no esôfago torácico distal pela proximidade da junção esofagogástrica (ADAMAMAMORAITOU et al., 2002), sendo normalmente evidenciado uma ou duas semanas após o evento inicial (SELLON \& WILLARD, 2003). Os sinais clínicos dependem da localização e da intensidade da estenose e incluem os mesmos da esofagite, porém com evidente perda de peso (WILLARD \& WEYRAUCH, 2000; ADAMAMA-MORAITOU et al., 2002; SELLON \& WILLARD, 2003).

Efeitos dos fármacos anestésicos

Estudos comprovam que alguns agentes pré-anestésicos e a maioria daqueles comumente usados para a indução e manutenção anestésica, reduzem o tônus do EEG e interferem no mecanismo fisiológico de esvaziamento esofágico, predispondo ao desenvolvimento do RGE (STROMBECK \& HARROLD, 1985; ADAMAMA-MORAITOU et al., 2002; WILSON et al., 2005, 2006a,b, 2007). A incidência do RGE em função do protocolo anestésico é descrita na tabela 1 .

A melhor variável para avaliar a possibilidade de ocorrência do RGE é a barreira de pressão, que representa a diferença entre o tônus do EEG e a pressão gástrica. A redução desta variável está associada com o refluxo ou com maior risco deste ocorrer. Desse modo, fármacos anestésicos que reduzem o tônus do EEG, diminuem a eficácia da barreira de pressão, predispondo

Tabela 1 - Ocorrência de episódios de refluxo gastroesofágico (RGE) em cães durante a anestesia geral com diferentes protocolos anestésicos.

\begin{tabular}{llcc}
\hline Autores & Agentes anestésicos & Número de cães & RGE (\%) \\
\hline GALATOS \& RAPTOPOULOS (1995a) & P., tiopental, halotano & 240 & 16,3 \\
GALATOS \& RAPTOPOULOS (1995b) & V., tiopental, halotano & 270 & 17,4 \\
RAPTOPOULOS \& GALATOS (1997) & P., tiopental, halotano & 34 & 17,6 \\
RAPTOPOULOS \& GALATOS (1997) & P., propofol, halotano & 34 & 50 \\
WILSON et al. (2005) & A., M., tiopental, isofluorano & 60 & 55 \\
WILSON et al. (2006b) & A., M., tiopental, isofluorano & 30 & 46,6 \\
WILSON et al. (2006b) & A., M., tiopental, halotano & 30 & 63,3 \\
WILSON et al. (2006b) & A., M., tiopental, sevofluorano & 30 & 60 \\
WILSON et al. (2006a) & A., M., tiopental, isofluorano & 20 & 55 \\
WILSON et al. (2007) & A., M., tiopental, isofluorano & 20 & 55 \\
WILSON et al. (2007) & A., Me., tiopental, isofluorano & 20 & 40 \\
WILSON et al. (2007) & Me., tiopental, isofluorano & 20 & 25 \\
ANAGNOSTOU et al. (2009) & A., tiopental, halotano & 7 & 14,3 \\
PANTI et al. (2009) & A, Met., propofol, isofluorano & 25 & 52 \\
FAVARATO (2010) & A, propofol, isofluorano & 30 & 13,3 \\
\hline
\end{tabular}

P. - proprionilpromazina; V. - pré-medicações variadas; A. - acepromazina; M. - morfina; Me. - meperidina; Met. - metadona. 
aos episódios de RGE (STROMBECK \& GUILFORD, 1996; ANAGNOSTOU et al., 2009).

Poucos agentes anestésicos atualmente em uso tiveram seus efeitos sobre o tônus do EEG avaliados (WILSON et al., 2007). A redução do tônus do EEG durante procedimentos anestésicos aumenta o risco de RGE, de modo que durante a anestesia geral é a causa mais comum de esofagite (GALATOS \& RAPTOPOULOS, 1995a,b; GALATOS et al., 2001) e da formação de estenose esofagiana no cão, embora poucos animais as desenvolvam após o procedimento anestésico (RAPTOPOULOS \& GALATOS, 1997; ADAMAMA-MORAITOU et al., 2002).

O episódio de RGE inicia-se usualmente após a indução anestésica, de modo que pode esse episódio ocorrer durante procedimentos cirúrgicos de curta duração (GALATOS \& RAPTOPOULOS, 1995a,b; RAPTOPOULOS \& GALATOS, 1997; GALATOS et al., 2001). Contudo, a anestesia prolongada resulta numa maior exposição do esôfago ao conteúdo refluído, aumentando o risco de lesão da mucosa (GALATOS et al., 2001).

Alguns agentes pré-anestésicos estudados mostraram reduzir o tônus do EEG nos cães. HALL et al. (1987) relataram redução em $35 \%$ do tônus fisiológico após aplicação da acepromazina, que se deve, provavelmente, a sua ação anticolinérgica, antihistamínica, antidopaminérgica, antiserotoninérgica e bloqueadora $\alpha$-adrenérgica. $\mathrm{O}$ diazepam, fármaco benzodiazepínico, está associado com a redução de $42 \%$ do tônus do EEG, porém o mecanismo ainda é incerto. Já a morfina é um potente analgésico narcótico e sua administração aumenta substancialmente a incidência de RGE durante o procedimento anestésico (WILSON et al., 2005). A atropina causa redução acentuada do tônus do EEG, que se deve à ação anticolinérgica sobre a musculatura do esfíncter esofagogástrico (STROMBECK \& HARROLD, 1985; STROMBECK \& GUILFORD, 1996).

Resultados divergentes foram atribuídos à administração da meperidina em cães, um analgésico opioide, que está associado ao aumento do tônus do EEG e à redução em $55 \%$ da incidência do RGE, quando comparada à acepromazina e à morfina (WILSON et al., 2007). A elevação do tônus do EEG está associada à característica desse fármaco em causar a degranulação dos mastócitos, com consequente aumento dos níveis teciduais e sanguíneos de histamina, que se liga aos receptores $\mathrm{H}_{1}$ no EEG, promovendo fortes contrações (STROMBECK \& HARROLD, 1985; WILSON et al., 2007).

A indução anestésica com propofol resulta em maior incidência de RGE quando comparado com o tiopental em cães (RAPTOPOULOS \& GALATOS, 1997). De forma semelhante, WATERMAN \& HASHIM (1992) demonstraram que a indução anestésica realizada tanto com o propofol quanto com o tiopental reduz o tônus do EEG e a barreira de pressão, sendo a maior redução dessas variáveis observadas com o propofol.

Os anestésicos voláteis também reduzem o tônus do EEG. HASHIM et al. (1995) demonstraram, em cães submetidos a procedimentos cirúrgicos intraabdominais e não abdominais, pela técnica de manometria esofágica, que a manutenção anestésica com isofluorano causou maior redução do tônus do EEG do que a anestesia mantida com halotano. Por outro lado, embora tenham observado episódios de refluxo, pela técnica de pHmetria esofágica, com os diferentes anestésicos voláteis testados, WILSON et al. (2006b) não encontraram diferença no risco de desenvolvimento do RGE em cães mantidos com isofluorano, halotano ou sevofluorano durante a realização de procedimentos cirúrgicos ortopédicos.

Métodos de diagnóstico dos episódios de refluxo gastroesofágico

Monitorização do pH intra-luminal esofágico (pHmetria esofágica)

A mensuração do $\mathrm{pH}$ intra-esofágico é considerada uma das provas mais sensíveis e específicas para a detecção da doença do refluxo gastroesofágico em humanos (MORAES FILHO, 1993; WILSON et al., 2005; POHL \& TUTUIAN, 2009). Na medicina veterinária, inúmeras pesquisas utilizaram a pHmetria esofágica com a finalidade de avaliar a incidência de episódios de RGE durante procedimentos anestésicos. Essa técnica tornou possível o reconhecimento daqueles animais que apresentavam refluxo não identificado visualmente como regurgitação, bem como possibilitou identificar alguns agentes anestésicos que predispõem ao quadro (GALATOS \& RAPTOPOULOS, 1995a,b; RAPTOPOULOS \& GALATOS, 1997; WILSON et al., 2005, 2006a,b, 2007, ANAGNOSTOU et al., 2009; PANTI et al., 2009).

A pHmetria esofágica consiste na introdução de um cateter equipado com sensores de $\mathrm{pH}$, na luz esofágica, a $5 \mathrm{~cm}$ do EEG. Esse cateter é ligado a um aparelho de registro portátil computadorizado que permite a monitoração do número e duração dos episódios de RGE por períodos de 24 horas ou mais (MORAES FILHO, 1993). Atualmente, está disponível um método de pHmetria esofágica sem fio, no qual uma pequena cápsula contendo um sensor de $\mathrm{pH}$ é posicionada na mucosa esofágica distal através da 
esofagoscopia. Essa cápsula envia os valores do $\mathrm{pH}$ esofágico através de ondas de rádio para um receptor externo em que os dados são armazenados (HONG \& VAEZI, 2009; POHL\& TUTUIAN, 2009). OpH esofágico obtido em cães, imediatamente após a indução anestésica, difere pouco entre os trabalhos publicados, sendo de 5,76 $\pm 0,62$, de acordo com WILSON et al. (2006a) e de 6,42 $\pm 0,65$, segundo RAPTOPOULOS \& GALATOS (1997).

Embora a pHmetria esofágica seja considerada uma excelente técnica para o diagnóstico do refluxo ácido, ela é pouco sensível para o diagnóstico do refluxo não ácido (KAUER et al., 1995). Considera-se refluxo ácido quando o $\mathrm{pH}$ reduz abruptamente para valores inferiores a 4 (GALATOS \& RAPTOPOULOS, 1995a; GALATOS et al., 2001; WILSON et al., 2005, 2006a; ANAGNOSTOU et al., 2009). Um estudo mostrou que $87 \%$ das exposições esofágicas à bilirrubina ocorriam com valores fisiológicos de $\mathrm{pH}$ local (entre $4 \mathrm{e} 7$ ), explicando a falha da pHmetria convencional na deteç̧ão desse fenômeno (KAUER et al., 1995).

Monitorização da bilirrubina no lúmen esofágico

A importância do refluxo não ácido na patogênese da doença de refluxo gastroesofágico vem sendo o foco de muitos estudos. Como a pHmetria convencional falha em detectar precisamente esse tipo de enfermidade, um método de diagnóstico disponível para o uso clínico é o registrador espectrofotométrico portátil de 24 horas. O sistema utiliza uma sonda de fibra óptica que mensura a absorbância da luz em um comprimento de onda de $470 \mathrm{~nm}$, sendo que valores acima de $0,14 \mathrm{~nm}$ são considerados indicativos da presença de bilirrubina no material refluído. De modo similar a pHmetria, o sensor de bilirrubina é posicionado no esôfago a $5 \mathrm{~cm}$ do limite superior do EEG (POHL \& TUTUIAN, 2009).

Impedância intra-luminal multicanal

Este método permite detectar o RGE de modo independente da detecção do pH. Baseia-se nas mudanças da condutibilidade elétrica intra-luminal, durante a passagem do conteúdo esofágico por um segmento contendo diversos eletrodos. Permite uma análise qualitativa dos vários tipos de conteúdos refluídos (gás e líquidos), pelo fato de cada um deles possuir uma característica diferente de condutibilidade elétrica. Essa técnica permite também determinar o sentido do fluxo do conteúdo e, desse modo, diferenciar o processo de deglutição (sentido aboral) do episódio de refluxo (sentido oral) (POHL \& TUTUIAN, 2009).
Avaliação endoscópica

O diagnóstico definitivo da esofagite e das estenoses esofágicas necessita da demonstração das anormalidades esofagianas pela esofagoscopia ou pelo esofagograma contrastado. Sabe-se que a esofagoscopia é a técnica mais sensível para o diagnóstico de esofagite (WILLARD \& WEYRAUCH, 2000; SELLON \& WILLARD, 2003), pois permite a documentação de alterações da mucosa, além da realização de biópsias para exames histopatológicos. Em humanos, a esofagoscopia possui baixa sensibilidade para a detecção do RGE, pois muitas vezes o conteúdo refluído não é visualizado no lúmen esofágico e pode não haver alterações inflamatórias características da enfermidade no momento de execução do exame (MORAES FILHO, 1993). Entretanto, FAVARATO (2010) observou que, quando realizada no final da anestesia geral em cães, a esofagoscopia é um bom método para diagnóstico do episódio de RGE, pois permite a visualização direta do conteúdo refluído (secreções e alimentos) no esôfago, devido à inibição dos reflexos peristálticos esofágicos ocasionada pelos anestésicos gerais.

As anormalidades endoscópicas observadas em pacientes com esofagite refletem a severidade da lesão esofagiana. A esofagite classificada como discreta pode ser apenas acompanhada por hiperemia ao longo das dobras da mucosa. Hiperemia mais extensa com sangramento iatrogênico ou espontâneo é observada nas esofagites de grau moderado. Nas inflamações severas, estão presentes os sinais anteriores, além de erosões e ulcerações (SELLON \& WILLARD, 2003).

A maioria das estenoses esofágicas pode ser detectada mediante a utilização da esofagoscopia (SELLON \& WILLARD, 2003). São caracterizadas pela redução do lúmen esofágico e podem estar presentes em qualquer extensão do esôfago. A avaliação do esôfago, distal à estenose, pode ser prejudicada, pois muitas vezes o diâmetro da lesão impossibilita a passagem do endoscópio. Algumas estenoses podem ser despercebidas à esofagoscopia, principalmente em cães de raças grandes, pois o diâmetro esofágico na estenose pode ser maior que o do endoscópio, permitindo a passagem deste sem dificuldade. Isso ocorre principalmente quando a estenose está localizada próximo ao EEG (WILLARD \& WEYRAUCH, 2000; SELLON \& WILLARD, 2003).

Terapia e prevenção do refluxo gastroesofágico em cães

Efeitos dos procinéticos gastrointestinais

No trato gastrointestinal, a dopamina está presente em quantidades significativas e produz efeito 
inibitório na motilidade gástrica através da supressão da liberação de acetilcolina, incluindo redução do tônus do esfíncter esofágico caudal, das contrações gástricas, da pressão intra-gástrica e das contrações antroduodenais, mediante ação nos receptores dopaminérgicos $\mathrm{D}_{2}$ (WILLEMS et al., 1985). O bloqueio desses receptores inibitórios por fármacos antagonistas resulta no efeito procinético (TONINI et al., 1999; PASRICHA, 2006). Alguns fármacos antidopaminérgicos interagem com os receptores serotoninérgicos, contribuindo para o efeito procinético (TONINI et al., 1999). A serotonina desencadeia o reflexo peristáltico por estimular os neurônios sensoriais intrínsecos do plexo mioentérico (via receptor $5-\mathrm{HT}_{4}$ ), bem como dos neurônios sensoriais vagais e espinhais extrínsecos (via receptor 5- $\mathrm{HT}_{3}$ ). Além disso, o estímulo dos receptores $5-\mathrm{HT}_{4}$ dos neurônios motores excitatórios eleva a liberação de acetilcolina na junção neuromuscular, aumentando a contração muscular (PASRICHA, 2006).

A metoclopramida é um fármaco procinético amplamente utilizado na medicina veterinária (SELLON \& WILLARD, 2003; TAMS, 2005). Os mecanismos de ação envolvem o estímulo dos receptores $5-\mathrm{HT}_{4}$, o antagonismo vagal e central dos receptores $5-\mathrm{HT}_{3} \mathrm{e}$, possivelmente, a sensibilização dos receptores muscarínicos dos músculos lisos, além do antagonismo dos receptores da dopamina. É um dos mais antigos agentes procinéticos e sua administração provoca contrações coordenadas que aceleram o trânsito no trato gastrointestinal superior (humanos), aumentando o tônus do EEG e estimulando as contrações do antro gástrico e do intestino delgado, principalmente pelo antagonismo dos receptores $\mathrm{D}_{2}$ nas fibras musculares lisas (PASRICHA, 2006).

Algumas pesquisas testaram o efeito preventivo da metoclopramida na incidência de RGE em cães anestesiados. WILSON et al. (2006a) observaram menor incidência do refluxo quando esse fármaco foi administrado em doses elevadas antes e durante a anestesia com acepromazina, morfina, tiopental e isofluorano. Entretanto, FAVARATO (2010) não observou esse efeito preventivo ao administrar a mesma dose de metoclopramida em cães anestesiados com acepromazina, propofol e isofluorano, embora tenha constatado menor frequência de RGE no grupo tratado quando comparado com o grupo controle. Uma possibilidade para a falha em demonstrar o benefício desse medicamento na prevenção dos episódios de refluxo pode ser o fato de o protocolo anestésico utilizado não ter proporcionado uma elevada incidência do RGE.
Efeitos dos inibidores da bomba de prótons

Os fármacos inibidores da bomba de prótons atuam na etapa final da secreção ácida e são eficientes na inibição da acidez, independentemente de outros fatores estimuladores. Inibem a secreção ácida por se ligarem seletivamente ao íon $\mathrm{H}^{+} \mathrm{e} \mathrm{K}^{+}$-ATPase, presente na célula parietal. A secreção de ácido somente é retomada após a síntese de novas moléculas da bomba, pois esses inibidores de prótons se unem através de ligações covalentes, inativando a bomba de forma irreversível (HOOGERWERF \& PASRICHA, 2006).

PANTI et al. (2009) observaram, em cães, que a administração de omeprazol algumas horas antes da anestesia reduziu a incidência dos episódios de RGE durante o procedimento, o que sustenta a observação de que a redução da acidez gástrica aumenta a competência do EEG (CASTELL, 1975; NG \& SMITH, 2001).

Efeitos dos inibidores de receptores $\mathrm{H}_{2}$

Os fármacos antagonistas dos receptores $\mathrm{H}_{2}$ reduzem a acidez gástrica por inibirem a produção de ácido ao competir com a histamina de forma reversível, pela sua ligação aos receptores $\mathrm{H}_{2}$ na membrana basolateral das células parietais (HOOGERWERF \& PASRICHA, 2006). Além disso, doses terapêuticas de ranitidina aumentam as contrações do antro gástrico, devido à inibição da acetilcolinesterase, efeito agonista colinérgico direto ou aumento da liberação neuronal de acetilcolina, o que lhes confere o efeito procinético com capacidade de aumentar o tônus do EEG (PARKMAN et al., 1998).

Foi demonstrado que a redução da acidez gástrica aumenta o tônus do EEG (CASTELL, 1975; NG \& SMITH, 2001). Entretanto, FAVARATO (2010) não observou melhora significativa da incidência de refluxo entre o grupo de cães tratado com ranitidina por via intravenosa 6 horas antes da anestesia, comparado ao grupo controle.

\section{CONCLUSÃO}

A ocorrência do refluxo gastroesofágico ocasionado por anestésicos gerais é um fator de risco para o desenvolvimento de complicações pósoperatórias, como a esofagite e estenose esofágica. $\mathrm{O}$ diagnóstico de episódios de refluxo pode ser realizado através da pHmetria, monitorização da bilirrubina e endoscopia esofágica, porém a impedância intra-luminal multicanal associada ao monitoramento do $\mathrm{pH}$ é a ferramenta diagnóstica mais precisa para sua identificação. Apesar de alguns estudos com procinéticos e inibidores da bomba de prótons 
apresentarem resultados positivos em reduzir a ocorrência do refluxo, outras pesquisas não confirmam esses achados, portanto mais investigações ainda são necessárias para estabelecer protocolos preventivos que possam ser realmente eficientes e empregados durante os procedimentos anestésicos.

\section{REFERÊNCIAS}

ADAMAMA-MORAITOU, K.K. et al. Benign esophageal stricture in the dog and cat: a retrospective study of 20 cases. Canadian Journal of Veterinary Research, v.66, n.1, p.5559, 2002. Disponível em: <http://www.ncbi.nlm.nih.gov/pmc/ articles/PMC226983/pdf/20020100s00010p55.pdf>. Acesso em: 06 abr. 2010.

ANAGNOSTOU, T.L. et al. Effect of endogenous progesterone and oestradiol-17beta on the incidence of gastro-oesophageal reflux and on the barrier pressure during general anaesthesia in the female dog. Veterinary Anaesthesia and Analgesia, v.36, n.4, p.308-318, 2009. Disponível em: <http:// www3.interscience.wiley.com/cgi-bin/fulltext/122382460/ HTMLSTART>. Acesso em: 06 abr. 2010. doi: 10.1111/j.14672995.2009.00462.x.

CASTELL, D.O. The lower esophageal sphincter. Physiologic and clinical aspects. Annals of Internal Medicine, v.83, n.3, p.390-401, 1975

FAVARATO, E.S. pHmetria esofágica e influência da metoclopramida e da ranitidina na prevenção dos episódios de refluxo gastroesofágico em cães anestesiados, submetidos a ovariosalpingohisterectomia eletiva. 2010. 95f. Tese (Doutorado em Medicina Veterinária) - Curso de Pós-graduação em Medicina Veterinária, Universidade Federal de Viçosa, MG

GALATOS, A.D. et al. Gastro-oesophageal reflux during thiopentone or propofol anaesthesia in the cat. Journal of Veterinary Medicine. Series A, Physiology, Pathology, Clinical Medicine, v.48, n.5, p.287-294, 2001. Disponível em: $<\mathrm{http} / / / w w w 3 . i n t e r s c i e n c e . w i l e y . c o m / c g i-b i n / f u l l t e x t / 119025318 /$ HTMLSTART>. Acesso em: 06 abr. 2010. doi: 10.1046/j.14390442.2001.00357.x.

GALATOS, A.D.; RAPTOPOULOS, D. Gastro-oesophageal reflux during anaesthesia in the dog: the effect of preoperative fasting and premedication. Veterinary Record, v.137, n.19, p.479-483, 1995a.

GALATOS, A.D.; RAPTOPOULOS, D. Gastro-oesophageal reflux during anaesthesia in the dog: the effect of age, positioning and type of surgical procedure. Veterinary Record, v.137, n.20, p.523-516, 1995 b.

HALL, J.A. et al. Effect of acepromazina, diazepam, fentanyldroperidol, and oxymorphone on gastroesophageal sphincter pressure in healthy dogs. American Journal of Veterinary Research, v.48, n.4, p.556-557, 1987.

HASHIM, M.A. et al. A comparasion of the effects of halothane and isofluorano in combination with nitrous oxide on lower oesophageal sphincter pressure and barrier pressure in anaesthetized dogs. Veterinary Record, v.137, n.26, p.658$661,1995$.
HONG, S.K.; VAEZI, M.F. Gastroesophageal reflux monitoring: $\mathrm{pH}$ (catheter and capsule) and impedance. Gastrointestinal Endoscopy Clinics of North America, v.19, n.1, p.1-22, 2009. Disponível em: <http://www.nature.com/gimo/contents/ pt1/full/gimo31.html>. Acesso em: 06 abr. 2010. doi: 10.1038/ gimo31.

HOOGERWERF, W.A.; PASRICHA, P.J. Farmacoterapia da acidez gástrica, úlceras pépticas e doença do refluxo gastroesofágico. In: BRUNTON, L.L. Goodman \& Gilman: as bases farmacológicas da terapêutica. Rio de Janeiro: McGraw-Hill, 2006. Cap.36, p.869-881.

KAUER, W.K. et al. Mixed reflux of gastric and duodenal juices is more harmful to the esophagus than gastric juice alone. The need for surgical therapy re-emphasized. Annals of Surgery, v.222, n.4, p.525-531, 1995. Disponível em: <http:/ /www.ncbi.nlm.nih.gov/pmc/articles/PMC1234886/>. Acesso em: 06 abr. 2010.

MORAES FILHO, J.P.P. Doença do refluxo gastroesofágico. In: DANI, R.; CASTRO, L.P. Gastroenterologia clínica. 3.ed. Rio de Janeiro: Guanabara Koogan, 1993. p.372-384.

MUIR, W.W. Considerations for general anesthesia. In: TRANQUILI, W.J. et al. Lumb \& Jones' veterinary anesthesia and analgesia. 4.ed. Iowa: Blackwell Publishing, 2007. p. 7-30.

NASI, A. et al. Doença do refluxo gastroesofágico: revisão ampliada. Arquivos de Gastroenterologia, v.43, n.4, p.334-341, 2006. Disponível em: < http://www.scielo.br/ scielo.php? script=sci arttext \& pid=S $0004-$ $28032006000400017 \& \operatorname{lng}=\mathrm{en} \& \mathrm{nrm}=\mathrm{iso} \& \mathrm{t} \operatorname{lng}=\mathrm{pt}>$. Acesso em: 06 abr. 2010.

NG, A; SMITH, G. Gastroesophageal reflux and aspiration of gastric contents in anesthetic practice. Anesthesia and Analgesia, v.93, n.2, p.494-513, 2001. Disponível em: < $\mathrm{http}: / / \mathrm{www}$.anesthesia-analgesia.org/content/93/2/ 494.full.pdf+html>. Acesso em: 28 jul. 2010.

PANTI, A. et al. The effect of omeprazole on oesophageal $\mathrm{pH}$ in dogs during anaesthesia. Journal of Small Animal Practice, v.50, n.10, p.540-544, 2009. Disponível em: <http:/ /www3.interscience.wiley.com/cgi-bin/fulltext/122614758/ PDFSTART>. Acesso em: 06 abr. 2010. doi: 10.1111/j.17485827.2009.00818.x.

PARKMAN, H.P. et al. Effect of gastric suppressants on human gastric motility. Gut, v.42, n.2, p.243-250, 1998. Disponível em: <http://gut.bmj.com/content/42/2/243.full>. Acesso em: 06 abr. 2010. doi: 10.1136/gut.42.2.243.

PASRICHA, P.J. Tratamento dos distúrbios da motilidade intestinal e do fluxo da água; antieméticos; fármacos usados nas doenças biliares e pancreáticas. In: BRUNTON, L.L. Goodman \& Gilman: as bases farmacológicas da terapêutica. Rio de Janeiro: McGraw-Hill, 2006. Cap.37, p.883-906.

POHL, D.; TUTUIAN, R. Reflux monitoring: pH-metry, Bilitec and oesophageal impedance measurements. Best Practice \& Research. Clinical Gastroenterology, v.23, n.3, p.299-311, 2009.

RAPTOPOULOS, D.; GALATOS, A.D. Gastro-oesophageal reflux during anaesthesia induced with either thiopentone or propofol in 
the dog. Journal of Veterinary Anaesthesia, v.2, n.1, p.2022, 1997. Disponível em: <http://www3.interscience.wiley.com/ cgi-bin/fulltext/119831740/PDFSTART>. Acesso em 06 abr. 2010. doi: 10.1111/j.1467-2995.1997.tb00263.x.

SAVVAS, I. et al. The effect of pre-anaesthetic fasting time and type of food on gastric content volume and acidity in dogs. Veterinary Anaesthesia and Analgesia, v.36, n.6, p.539546, 2009. Disponível em: < http://www3.interscience.wiley.com/ cgi-bin/fulltext/122652437/PDFSTART>. Acesso em: 28 jul. 2010. doi: 10.1111/j.1467-2995.2009.00495.x.

SELLON, R.K.; WILLARD, M.D. Esophagitis and esophageal strictures. Veterinary Clinics of North America: Small Animal Practice, v.33, n.5, p.945-967, 2003.

STROMBECK, D.R.; GUILFORD, W.G. Pharynx and esophagus: normal structure and function. In: GUILFORD, W.G. et al. Strombeck's small animal gastroenterology. Philadelphia: Saunders, 1996. Cap.10, p.202-210.

STROMBECK, D.R.; HARROLD, D. Effect of gastrin, histamine, serotonin, and adrenergic amines on gastroesophageal sphincter pressure in the dog. American Journal of Veterinary Research, v.46, n.8, p.1684-1690, 1985 .

TAMS, T.R. Doenças do esôfago. In: Gastroenterologia de pequenos animais. São Paulo: Roca, 2005. Cap.4, p.115-153.

TONINI, M. et al. Review article: cardiac effects of gastrointestinal prokinetics. Alimentary Pharmacology \& Therapeutics, v.13, n.12, p.1585-1591, 1999. Disponível em: <http://www3.interscience.wiley.com/cgi-bin/fulltext/ 119089999/HTMLSTART>. Acesso em: 07 abr. 2010. doi: 10.1046/j.1365-2036.1999.00655.x.

WATERMAN, A.E.; HASHIM, M.A. Measurement of the length and position of the lower oesophageal sphincter by correlation of external measurements and radiographic estimations in dogs. Veterinary Record, v.129, n.12, p.261264, 1991.

WATERMAN, A.E.; HASHIM, M.A. Effects of thiopentone and propofol on lower oesophageal sphincter and barrier pressure in the dog. Journal of Small Animal Practice, v.33, n.11, p.530-533, 1992.

WILLARD, M.D.; WEYRAUCH, E.A. Esophagitis. In: BONAGURA, J.D. Kirk's current veterinary therapy XIII - small animal practice. Philadelphia: Saunders, 2000. Cap.8, p.607-617.

WILLEMS, J.L. et al. Neuronal dopamine receptors on autonomic ganglia and sympathetic nerves and dopamine receptors in the gastrointestinal system. American Society for Pharmacology and Experimental Therapeutics, v.37, n.2, p.165-216, 1985. Disponível em: <http:// pharmrev.aspetjournals.org/content/37/2/165.full.pdf $>$. Acesso em: 07 abr. 2010 .

WILSON, D.V. et al. Effects of pre-anesthetic administration of morfine on gastroesophageal reflux and regurgitation during anesthesia in dogs. American Journal of Veterinary Research, v.66, n.3, p.386-390, 2005.

WILSON, D.V. et al. Influence of metoclopramida on gastroesophageal reflux in anesthetized dogs. American Journal of Veterinary Research, v.67, n.1, p.26-31, 2006a.

WILSON, D.V. et al. Influence of halothane, isoflurane and sevoflurane on gastroesophageal reflux during anesthesia in dogs. American Journal of Veterinary Research, v.67, n.11, p.1821-1825, 2006b.

WILSON, D.V. et al. Pre-anesthetic meperidina: associated vomiting and gastroesophageal reflux during the subsequent anesthetic in dogs. Veterinary Anaesthesia and Analgesia, v.34, n.1, p.15-22, 2007. Disponível em: <http:// www3.interscience.wiley.com/cgi-bin/fulltext/118516528/ HTMLSTART>. Acesso em: 07 abr. 2010. doi: 10.1111/j.14672995.2006.00295.x. 